\title{
003 BP SERVICE USER PARTICIPATION IN QUALITATIVE MENTAL HEALTH RESEARCH: SHARING ADOLESCENTS' EXPERIENCES OF DEPRESSION THROUGH FILM
}

\author{
S Parkinson, ${ }^{1,2 *}$ V Dunn, ${ }^{3,4 *}$ E Stapley, ${ }^{1,2} \mathrm{~N}$ Midgley ${ }^{1,2}$. 'Anna Freud National \\ Centre for Children and Families, UK; ${ }^{2}$ Research Department of Clinical, Educational \\ and Health Psychology, University College London, UK; ${ }^{3}$ Creative Research Collective, \\ UK; ${ }^{4}$ National Institute of Health Research Collaboration for Leadership in Applied \\ Health Research and Care (NIHR CLAHRC) East of England, UKI Department of \\ Psychiatry, University of Cambridge, UK
}

\subsection{6/bmjopen-2017-016492.13}

IMPACT-My Experience (IMPACT-ME) is a qualitative study, which aimed to explore adolescents' experiences of depression and receiving therapy, as well as their parents' experiences. As researchers working on the study, our focus was on writing academic papers to disseminate what we were learning from the qualitative interviews with the young people and families. However, over the course of the project we started to think about how we could share our findings with a wider audience. In consultation with our advisory group of parents and young people, the idea of making short animated films based on our findings, which would be freely available on YouTube, came about. In four-day creative, participatory workshops, young people, parents, researchers, filmmakers and a group-work facilitator worked together to co-produce a trilogy of short films.

The first film, "Facing Shadows", shares the experiences of the young people. The second film, "Journey Through the Shadows", shares the perspectives of their parents. We also created a third short film to document the process of making these films, to share with a wider audience the value and process of service user participation in mental health research. The young people and parents were involved in all aspects of creating the films, which were premiered at the British Film Institute. Following an active social media campaign, the films have since been viewed over 10,000 times on YouTube. This presentation will share our reflections on working collaboratively with young people and families in mental health research. 